\title{
Editorial: Marine Litter Windrows
}

\author{
Stefano Aliani ${ }^{1,2 \star}$, Oihane C. Basurko ${ }^{3}$, Manuel Arias $^{4}$, Atsuhiko Isobe ${ }^{5}$, Anna Rubio ${ }^{3}$, \\ Konstantinos Topouzelis ${ }^{6}$ and Andrés Cózar ${ }^{2}$ \\ ${ }^{1}$ National Research Council, Institute Marine Science, Lerici, Italy, ${ }^{2}$ Departamento de Biología, Instituto Universitario de \\ Investigación Marina (INMAR), University of Cadiz and European University of the Seas (SEA-EU), Puerto Real, Spain, ${ }^{3}$ AZTI, \\ Marine Research, Basque Research and Technology Alliance (BRTA), Gipuzkoa, Spain, ${ }^{4}$ Institut de Ciéncies del Mar, Consejo \\ Superior de Investigaciones Científicas, Barcelona, Spain, ${ }^{5}$ Research Institute for Applied Mechanics, Kyushu University, \\ Fukuoka, Japan, ${ }^{6}$ Department of Marine Science, University of the Aegean, Mytilene, Greece
}

Keywords: floating plastic, surface slicks, marine debris, convergence zone, accumulation and transport

\section{Editorial on the Research Topic}

\section{Marine Litter Windrows}

Our civilization produced about 8,300 Mt of synthetic polymers to date (Geyer et al., 2017), and the seas and oceans are pooling much of them (González-Fernández et al., 2021). Figuring out how all this marine litter moves and where it accumulates is a challenging task (Van Sebille et al., 2020). In some cases, we have been able to describe the distribution of plastics at a large-scale and associated to steady circulation patterns (e.g., Cózar et al., 2014), but understanding plastic distribution at small scale is more complex, due to the also complex ocean dynamics at such scales, and the much shorter-lived structures resulting from it.

Actually, if we look at the ocean surface, it is common to see floating natural and man-made materials aggregated in small dense patches, often arranged in parallel lines sometime more than one kilometer long. They are traditionally called windrows in the scientific literature (Faller and Woodcock, 1964; Owen, 1965; Craik, 1970; Leibovich, 1983); foam lines, slicks, drift lines, rip lines, filaments, or streaks are synonyms. There is no definitive classification, but a listing of them would include windrows generated by tidal fronts, shelf-break fronts, upwelling fronts, river plumes, estuarine fronts, fronts associated with the convergence or divergence of water masses in the open ocean, frontal eddies, caused by internal waves, and fronts associated with geomorphologic features such as headlands, islands, and canyons (Mann and Lazier, 2006). All these processes are capable to create the surface evidence that we call windrows. In this volume, some aspects of ocean windrows are presented, focusing on the interaction of windrows with marine debris and related problems and opportunities.

The omnipresent presence of windrows in the world's ocean suggests that the global influence of these structures to surface plastics concentration is not negligible, and the load of plastics aggregated in windrows could be highly significant, and count for an important fraction of the plastic pollution floating at sea. A recent survey of $1,000 \mathrm{~km}^{2}$ of ocean surface off Hawaii demonstrated that surface convergence zones occupied only $8 \%$ of the surface, but they accumulated 92\% of all floating microplastics (Gove et al., 2019). Furthermore, biological productivity is usually high in windrows with increased chance of litter ingestion, entanglement or colonization of litter surfaces. The same mechanisms that help to concentrate plastic pollution, also help to concentrate natural-occurring nutrients and organic debris. In the perspective paper of this volume, Cózar et al. presented some possible interactions of windrows and biota, and highlighted new research questions. For example, high loads of floating litter in the environment results in the formation of more numerous and dense litter windrows, making it possible to monitor them from aerial surveys and even from space-borne sensors. Only a limited number of papers in the literature about plastics consider windrows, as of today. One of the major limits to field studies on windrows 
is our limited knowledge on how to spot them. Encouraging results from satellite data suggest that adaptative sampling design, when guided by remote sensing, may overcome the limited efficiency of at sea sightings.

Indeed, detection of windrows at sea from a ship is not easy, and sampling is constrained by the ephemeral nature of most of the slicks, which makes systematic field campaigns difficult. There are very few works addressing plastics in windrows. In a ship-based study presented in this volume by Ruiz et al. windrows in the Bay of Biscay have been described and plastics therein sampled. Most of windrows had around $1 \mathrm{~km}$ length and, on average, accumulated the remarkable amount of $77.75 \mathrm{~kg}$ of floating marine litter. This value is in fact more relevant to support an active collection at sea as the accumulation in windrows makes the collection easier than in a diluted scenario.

Gallardo et al. after a joint sampling of plastics and plankton in the coastal waters of Rapa Nui in the East Pacific, found a positive relationship between low mobility organisms, which could be compared to passive tracers, and plastics. The presence of predators and high mobility animals has been hypothesized as a consequence of the positive attraction of these high productive sites as hot sports for food sources. However, given the ephemeral nature of windrows, it is likely that interaction with plankton might be temporary and driven by the dynamics of the physical forcing that create windrows, for example wind regimes or seasonal changes in water currents. Thus, windrows with their ability to gather larvae, algae, particles organic matter, and predators may act as temporary moving oasis in a low productivity ocean.

Windrows seem to be usually generated also by internal waves. This phenomenon is particularly common on the continental shelves, where marine litter often accumulate in high concentrations (Pham et al., 2014; Morales-Caselles et al., 2021). Litter windrows generated by internal waves are aligned with the morphology of the seabed and not the wind, like those driven by Langmuir circulation. Windrows are related to a variety of surface convergence processes, which are not usually associated

\section{REFERENCES}

Cózar, A., Echevarría, F., González-gordillo, J. I., Irigoien, X., and Úbeda, B. (2014). Plastic debris in the open ocean. PNAS 111, 10239-10244. doi: 10.1073/pnas.1314705111

Craik, A. (1970). A wave-interaction model for the generation of windrows. J. Fluid Mech. 41, 801-821. doi: 10.1017/S0022112070000939

Faller, A. J., and Woodcock, A. H. (1964). The spacing of windrows of Sargassum in the ocean. J. Mar. Res. 22, 22-29.

Geyer, R., Jambeck, J. R., and Law, K. L. (2017). Production, use, and fate of all plastics ever made. Sci. Adv. 3, 25-29. doi: $10.1126 /$ sciadv.1700782

González-Fernández, D., Cózar, A., Hanke, G., Viejo, J., Morales-Caselles, C., Bakiu, R., et al. (2021). Floating macrolitter leaked from Europe into the ocean. Nat. Sustain. 4, 474-483. doi: 10.1038/s41893-021-00722-6

Gove, J. M., Whitney, J. L., McManus, M. A., Lecky, J., Carvalho, F. C., Lynch, J. M., et al. (2019). Prey-size plastics are invading larval fish nurseries. Proc. Natl. Acad. Sci. U.S.A. 116, 24143-24149. doi: 10.1073/pnas.1907496116 with important transport processes. However, in the particular case of converging structures induced by internal waves, they can move large distances by the wave propagation, so that transport is added to accumulation. In the present Research Topic volume, Shanks reviews the evidences of accumulation and transport of plankton, larvae or debris by internal waves. He points out some open questions about the role of windrows associated to internal waves on floating plastic concentration and transport. This is an important factor, as systematic observation of windrows could be a very valuable and unique source of information, to better understand ocean dynamics at spatial and temporal scales of which we have a poor knowledge.

Research on plastics in windrows is key to understand global marine litter. We have efficient methods to study the physical-chemical and biological properties but the challenge for the field samplings remains to forecast the formation and duration of windrows on ocean's surface. Improving our prediction and detection capabilities would open up great prospects for research and management of marine litter, as well as for Marine Ecology and Physical Oceanography.

\section{AUTHOR CONTRIBUTIONS}

SA and AC planned and wrote the text. All authors contributed to the discussion and writing.

\section{FUNDING}

This editorial is an outcome of the following research projects: ESA WASP, ESA PLP, PRIN WERYZP EMME, JPI Oceans FACTS, PNRA IPSODES, PLASTREND (BBVA Foundation) and MIDaS (CTM2016-77106-R, AEI/FEDER/UE), JERICOS3, LIFE LEMA, Environmental Research and Technology Development Fund (JPMEERF18S20201) of the Ministry of the Environment, Japan, and SATREPS of Japan International Cooperation Agency and Japan Science and Technology Agency.

Leibovich, S. (1983). The form and dynamics of Langmuir circulations. Annu. Rev. fluid Mech. 15, 391-427. doi: 10.1146/annurev.fl.15.010183.002135

Mann, K. H., and Lazier, J. R. N. (2006). Dynamics of Marine Ecosystems: Biological-Physical Interactions in the Oceans, $3 r d$ Edn. Malden, MA: Blackwell Publication.

Morales-Caselles, C., Viejo, J., Martí, E., and Al., E. (2021). An inshore-offshore sorting system revealed from global classification of ocean litter. Nat. Sustain. 4, 484-493. doi: 10.1038/s41893-021-00720-8

Owen, R. W. (1965). Small-scale, horizontal vortices in the surface layer of the sea. J. Mar. Res. 24, 56-66.

Pham, C. K., Ramirez-Llodra, E., Alt, C. H., Amaro, T., Bergmann, M., Canals, M., et al. (2014). Marine litter distribution and density in european seas, from the shelves to deep basins. PLOS ONE 9:e95839. doi: 10.1371/journal.pone.0095839

Van Sebille, E., Aliani, S., Law, K. L., Maximenko, N., Alsina, J. M., Bagaev, A., et al. (2020). The physical oceanography of the ransport of floating marine debris. Environ. Res. Lett. 15:023003. doi: 10.1088/1748-9326/ab6d7d 
Conflict of Interest: The authors declare that the research was conducted in the absence of any commercial or financial relationships that could be construed as a potential conflict of interest.

Publisher's Note: All claims expressed in this article are solely those of the authors and do not necessarily represent those of their affiliated organizations, or those of the publisher, the editors and the reviewers. Any product that may be evaluated in this article, or claim that may be made by its manufacturer, is not guaranteed or endorsed by the publisher.

Copyright (c) 2022 Aliani, Basurko, Arias, Isobe, Rubio, Topouzelis and Cózar. This is an open-access article distributed under the terms of the Creative Commons Attribution License (CC BY). The use, distribution or reproduction in other forums is permitted, provided the original author(s) and the copyright owner(s) are credited and that the original publication in this journal is cited, in accordance with accepted academic practice. No use, distribution or reproduction is permitted which does not comply with these terms. 